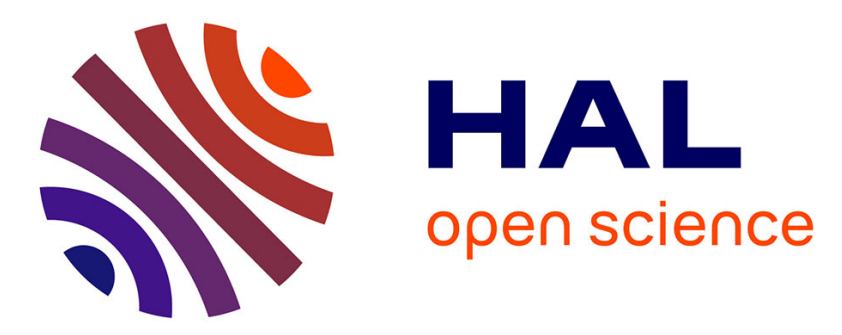

\title{
Synthesis of multi-walled carbon nanotubes by combining hot-wire and dc plasma-enhanced chemical vapor deposition
}

Costel Sorin Cojocaru, Dohyung Kim, Didier Pribat, Jean Eric Bouree

\section{To cite this version:}

Costel Sorin Cojocaru, Dohyung Kim, Didier Pribat, Jean Eric Bouree. Synthesis of multi-walled carbon nanotubes by combining hot-wire and dc plasma-enhanced chemical vapor deposition. Thin Solid Films, 2006, 501, pp.227-232. 10.1016/j.tsf.2005.07.162 . hal-00541129

\author{
HAL Id: hal-00541129 \\ https://hal.science/hal-00541129
}

Submitted on 2 Mar 2013

HAL is a multi-disciplinary open access archive for the deposit and dissemination of scientific research documents, whether they are published or not. The documents may come from teaching and research institutions in France or abroad, or from public or private research centers.
L'archive ouverte pluridisciplinaire HAL, est destinée au dépôt et à la diffusion de documents scientifiques de niveau recherche, publiés ou non, émanant des établissements d'enseignement et de recherche français ou étrangers, des laboratoires publics ou privés. 


\title{
Thin Solid Films \\ 501 (2006) $227-232$ \\ doi:10.1016/j.tsf.2005.07.162
}

\section{Synthesis of multi-walled carbon nanotubes by combining hot-wire and dc plasma-enhanced chemical vapor deposition}

\author{
Costel Sorin Cojocaru, Dohyung Kim, Didier Pribat, Jean-Eric Bourée*
}

Laboratoire de Physique des Interfaces et des Couches Minces, CNRS UMR 7647, Ecole Polytechnique, F-91128 Palaiseau Cedex, France

\begin{abstract}
Multi-walled carbon nanotubes (MWCNTs) have been grown on $7 \mathrm{~nm}$ Ni-coated substrates consisting of crystalline silicon covered with a thin layer (10 nm) of TiN, by combining hot-wire chemical vapor deposition (HWCVD) and direct current plasma-enhanced chemical vapor deposition (dc PECVD), at 620 -C. Acetylene $\left(\mathrm{C}_{2} \mathrm{H}_{2}\right)$ gas is used as the carbon source and ammonia $\left(\mathrm{NH}_{3}\right)$ and hydrogen $\left(\mathrm{H}_{2}\right)$ are used either for dilution or etching. The carbon nanotubes range from 20 to $100 \mathrm{~nm}$ in diameter and 0.3 to 5 Am in length, depending on growth conditions: plasma intensity, filament current, pressure, $\mathrm{C}_{2} \mathrm{H}_{2}, \mathrm{NH}_{3}, \mathrm{H}_{2}$ flow rates, $\mathrm{C}_{2} \mathrm{H}_{2} / \mathrm{NH}_{3}$ and $\mathrm{C}_{2} \mathrm{H}_{2} / \mathrm{H}_{2}$ mass flow ratios. By combining the HWCVD and the dc PECVD processes, uniform growth of oriented MWCNTs was obtained, whereas by using only the HWCVD process, tangled MWCNTs were obtained. By patterning the nickel catalyst, with the use of the HW dc PECVD process, uniform arrays of nanotubes have been grown as well as single free-standing aligned nanotubes, depending on the catalyst patterning (optical lithography or electron-beam lithography). In the latter case, electron field emission from the MWCNTs was obtained with a maximum emission current density of $0.6 \mathrm{~A} / \mathrm{cm}^{2}$ for a field of $16 \mathrm{~V} / \mathrm{Am}$.

KEYWORDS: Carbon nanotubes; Hot-wire assisted direct current plasma-enhanced chemical vapor deposition
\end{abstract}

\section{Introduction}

Since the discovery of carbon nanotubes (CNTs) in 1991 [1], there has been widespread interest in their use in a multitude of applications in nanoscale devices. Numerous studies have shown that multi-walled carbon nanotubes (MWCNTs) always exhibit metallic behavior and, due to their high aspect ratio (length/radius), can emit electrons in the neighborhood of their tips. These interesting electronic properties allow MWCNTs to be useful as new materials for the development of electron-field-emitting flat panel displays [2,3]. Although aligned CNTs are not strictly necessary for these applications, the use of aligned/micropatterned forms of CNTs has been shown to offer additional advantages for the development of low threshold field (electric field required for an electron field emission) nanotube-based flat-panel displays.
In the beginning, CNTs have been produced by arcdischarge or laser ablation. These high-temperature methods were the most useful because they could produce large amounts of nanotubes, but their common drawback was the number of impurities incorporated in the material, whose type and amount depended on the deposition technique. Along with controlling the CNT morphology and structure, many practical applications require as well the precise control of their orientation, alignment and density. Thus, the hightemperature methods have been replaced by several lowtemperature chemical vapor deposition (CVD) techniques $(<800-\mathrm{C})$, which are most promising in terms of CNT deterministic growth. These techniques include thermal CVD [4,5], direct current (dc) plasma-enhanced CVD (dc PECVD) [6,7], microwave PECVD [8-10], hot-wire (HW) dc PECVD [11-13], and HWCVD [14-16]. In all these techniques, substrates (c-Si or $\mathrm{SiO}_{2}$ coated c-Si) were coated with a suitable transition metal catalyst, primarily Fe, Co or Ni.

The present paper focuses on the synthesis of MWCNTs in a reactor combining both HWCVD and dc 


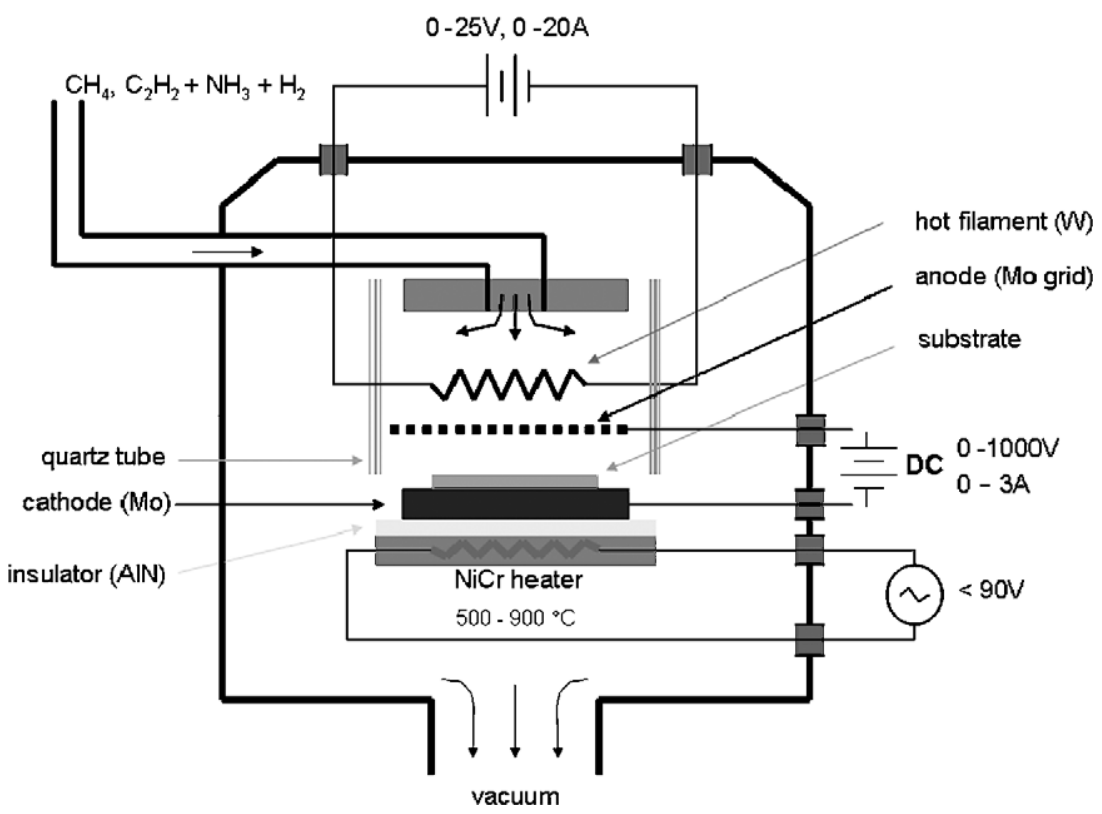

Fig. 1. Schematic cross-section of the experimental HW dc PECVD set-up.

PECVD techniques, using the $\mathrm{C}_{2} \mathrm{H}_{2} / \mathrm{NH}_{3} / \mathrm{H}_{2}$ gas mixture. The idea is that by comparing these two CVD processes separately or not, under identical deposition conditions, it should be possible to get a new insight into the understanding of the complex mechanism of CNT nucleation and growth. Thus, optimized growth conditions should be found, providing aligned MWCNTs with uniform diameters and lengths. Moreover, using patterning techniques such as optical or electron lithography in order to precisely locate the catalyst on the surface, this work shows that patterned arrays of aligned nanotubes can be deposited to ensure a significant electron emission current.

\section{Experimental details}

A stainless steel reactor (Fig. 1) containing one tungsten filament $(0.38 \mathrm{~mm}$ in diameter) and two molybdenum electrodes has been designed for the growth of carbon nanotubes. The tungsten filament coil is powered by a direct current (dc) source around 13 A (250 W), allowing the filament temperature to stabilize at 1800 -C. The cathode (substrate-holder) can be negatively dc-biased compared to the anode (Mo grid) up to $-450 \mathrm{~V}$ (with current densities between 1.5 and $4 \mathrm{~mA} / \mathrm{cm}^{2}$ ). The distance between the tungsten wire and the cathode is fixed to $15 \mathrm{~mm}$. An Ni-Cr heater, in thermal contact with the cathode but electrically

Table 1

Growth conditions for dc PECVD, HWCVD and combined HW dc PECVD processes

\begin{tabular}{|c|c|c|c|c|c|}
\hline Sample & Gas mixture, $\mathrm{C}_{2} \mathrm{H}_{2} / \mathrm{NH}_{3} / \mathrm{H}_{2}(\%)$ & Pressure (mbar) & $\mathrm{T}_{\mathrm{s}}(-\mathrm{C})$ & dc-PE activation, $\mathrm{V}_{\mathrm{A}-\mathrm{C}}(\mathrm{V}) \times \mathrm{J}_{\mathrm{C}}{ }^{\mathrm{a}}\left(\mathrm{mA} / \mathrm{cm}^{2}\right)$ & HW activation, $\mathrm{P}(\mathrm{W}) / \mathrm{T}_{\mathrm{f}}(-\mathrm{C})$ \\
\hline 1 & 10:00:90 & 1 & 620 & $486 \times 1.5$ & - \\
\hline 2 & $10: 20: 70$ & 1 & 620 & $365 \times 1.5$ & - \\
\hline 3 & $10: 40: 50$ & 1 & 620 & $360 \times 1.5$ & - \\
\hline 4 & $10: 60: 30$ & 1 & 620 & $370 \times 1.5$ & - \\
\hline 5 & 10:90:00 & 1 & 620 & $375 \times 1.5$ & - \\
\hline 6 & 10:00:90 & 1 & 620 & - & $250 / 1800$ \\
\hline 7 & $10: 50: 40$ & 1 & 620 & - & $250 / 1800$ \\
\hline 8 & 10:90:00 & 1 & 620 & - & $250 / 1800$ \\
\hline 9 & $10: 20: 70$ & 1 & 620 & $375 \times 1.5$ & 75/1100 \\
\hline 10 & $10: 20: 70$ & 1 & 620 & $375 \times 1.5$ & $150 / 1500$ \\
\hline 11 & $10: 20: 70$ & 1 & 620 & $375 \times 1.5$ & $250 / 1800$ \\
\hline 12 & 10:10:80 & 1 & 620 & $405 \times 1.5$ & $250 / 1800$ \\
\hline 13 & 10:05:85 & 1 & 620 & $420 \times 1.5$ & $250 / 1800$ \\
\hline 14 & 10:00:90 & 1 & 620 & $490 \times 1.5$ & $250 / 1800$ \\
\hline 15 & 7.5:2.5:90 & 3 & 660 & $375 \times 3$ & $250 / 1800$ \\
\hline
\end{tabular}

For all samples, the substrate consisted of $\mathrm{Ni}(7 \mathrm{~nm}) / \mathrm{TiN}(10 \mathrm{~nm}) / \mathrm{Si}(100)$, and the growth time was set to $15 \mathrm{~min}$.

${ }^{a} \mathrm{~V}_{\mathrm{A}-\mathrm{C}}$ : potential drop between the anode and the cathode; $\mathrm{J}_{\mathrm{C}}$ : current density of ions impinging on the cathode. 
insulated from it, can heat the cathode up to 700 -C. The base pressure of the deposition chamber is as low as $10^{-7}$ mbar. In the gas mixture used, acetylene is the deposition gas whereas ammonia and hydrogen are the etching gases. During the growth, a pressure ranging from 1 to 5 mbar is maintained in the reactor.

The nickel catalyst ( $7 \mathrm{~nm}$ thick) and the TiN diffusion barrier (10 nm thick) films were deposited onto doped silicon substrates. The diffusion barrier layer prevents the formation of $\mathrm{NiSi}_{\mathrm{x}}$ via $\mathrm{Ni}$ diffusion above $300-\mathrm{C}$ and maintains $\mathrm{Ni}$ particles for the catalytic nucleation and subsequent growth of the carbon nanotubes. Upon annealing to the growth temperature in the range 500 to $700-\mathrm{C}$, under $\mathrm{H}_{2}$ flow, with the help of the thermally activated HWCVD process (W filament heated at $1800-\mathrm{C}$ ), the nickel thin film was found to break up into nanoparticles which seed the growth of the MWCNTs. Owing to the studies of other groups $[5,7,9]$, it has been shown that the thickness of the initial $\mathrm{Ni}$ thin film and the growth temperature determine the size and density of the nanoparticles formed after annealing, and hence control the diameter and density of the nanotubes. After reaching the working temperature, the nanotube growth was initiated by introducing $\mathrm{NH}_{3}$ and $\mathrm{C}_{2} \mathrm{H}_{2}$ into the chamber and igniting the glow discharge plasma using a $1 \mathrm{~kW}$ dc generator between the anode and the heated substrate-holder, the distance between these electrodes being $8 \mathrm{~mm}$.

The surface morphology of the grown MWCNTs was investigated with a FEG high resolution scanning electron microscope whereas the carbon bonding and the micro-
A

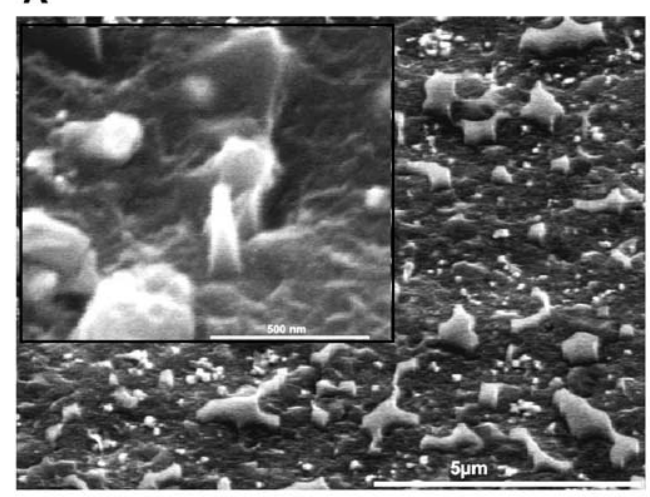

C

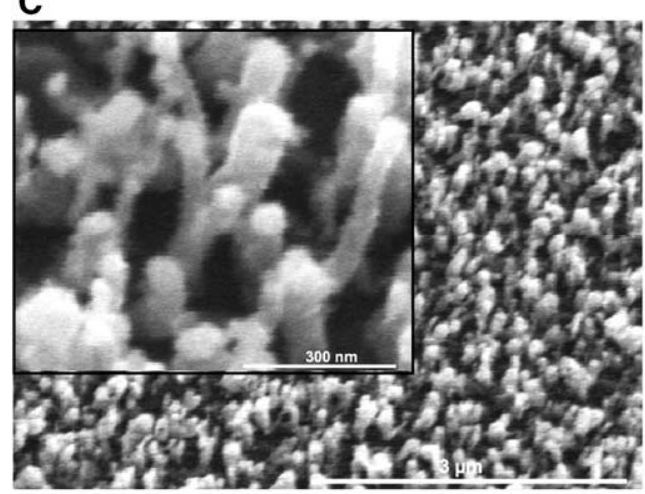

E

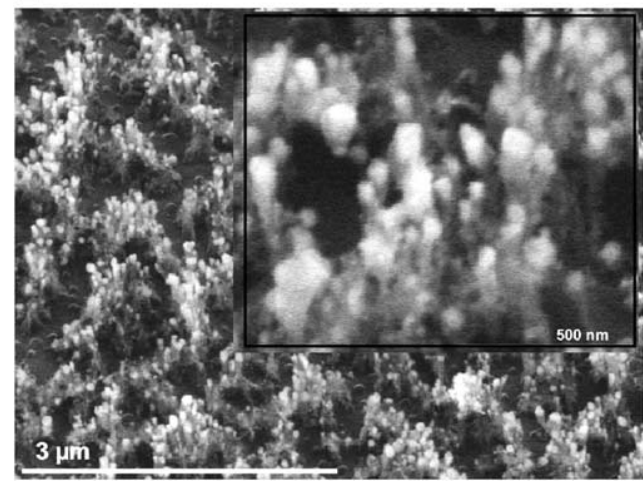

B

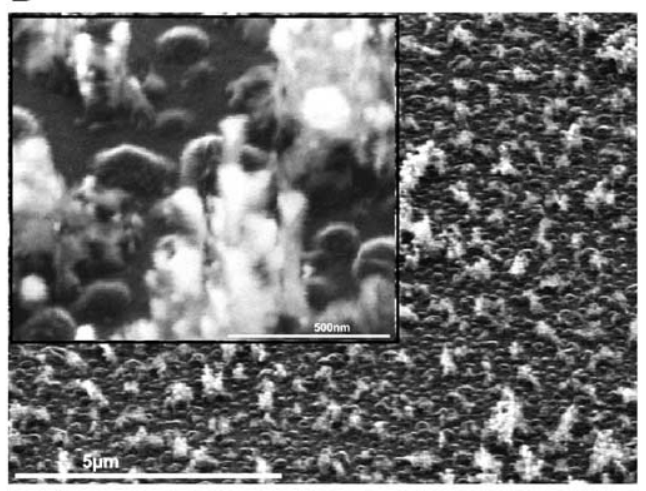

D

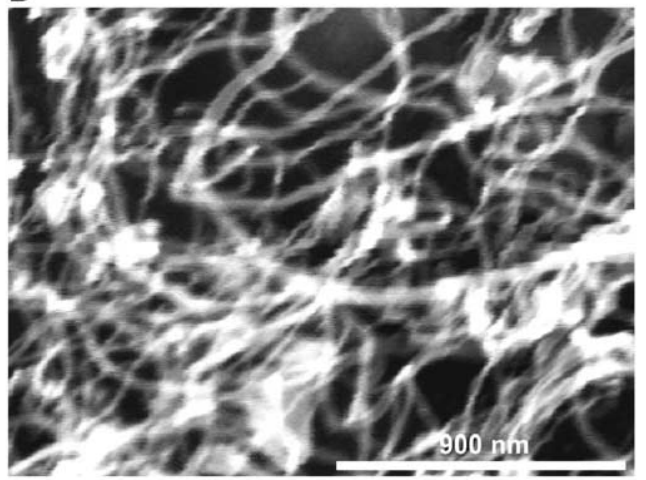

$\mathbf{F}$

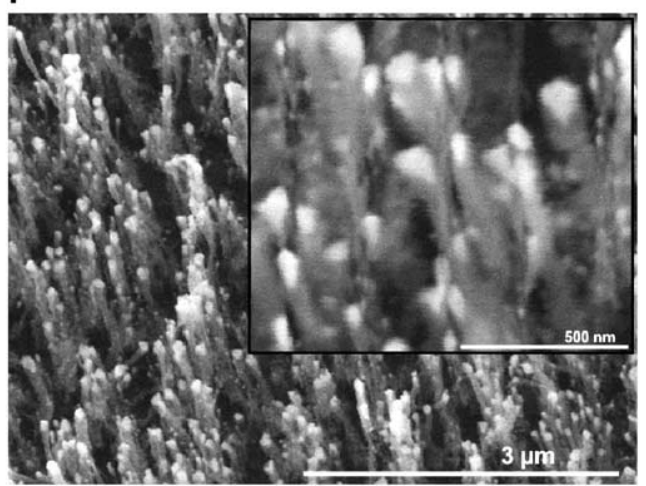

Fig. 2. Sequence of SEM images (observation angle 45-) on: (A) sample 1; (B) sample 2; (C) sample 5; (D) sample 7; (E) sample 12; (F) sample 13. 
structure were assessed by Raman spectroscopy and transmission electron microscopy, respectively. Electron field emission was carried out using a triode set-up in a vacuum chamber working at $10^{-6}$ Torr.

\section{Results and discussion}

Different types of growth processes, namely dc PECVD, HWCVD and combined HW dc PECVD were investigated as function of gas mixture composition, total pressure, activation power and geometrical configuration. Various $\mathrm{C}_{2} \mathrm{H}_{2} / \mathrm{NH}_{3} / \mathrm{H}_{2}$ ratios were used with a total gas flow rate of $100 \mathrm{sccm}$ (see the growth conditions in Table 1, samples 1 to 14). All syntheses were performed at 620 -C and 1 mbar total pressure with 15 min deposition time.

The dc PECVD growth mode was first studied for gas mixtures containing $10 \%$ acetylene and an increasing ammonia content diluted in hydrogen (see Table 1, samples 1 to 5). The dc PECVD process generates radicals and ions impinging on the cathode. Moreover, the dissociation energy for $\mathrm{NH}_{3}$ is lower than for $\mathrm{H}_{2}$ (a bias of 325V [17] is sufficient), so that atomic $\mathrm{H}$ is easily produced by the plasma. The current density of ions impinging on the cathode has been maintained to a fixed value of $1.5 \mathrm{~mA} / \mathrm{cm}^{2}$ while the potential drop between the electrodes could vary freely (current regulation mode) between $360 \mathrm{~V}$ and $480 \mathrm{~V}$. Fig. 2A is the SEM image corresponding to sample 1 prepared with no ammonia and high bias voltage: the deposited layer exhibits a large roughness with scarce whiskers. The associated Raman spectrum (Fig. 3) exhibits two intense D and G peaks around 1350 and $1590 \mathrm{~cm}^{-1}$ with two additional small bands around 1160 and 1500 $\mathrm{cm}^{-1}$, indicative of many $\mathrm{sp}^{3} \mathrm{C}$ defects. The graphitic contribution may be ascribed to the high voltage which generates some etching species. When 20\% ammonia is introduced in the gas mixture (sample 2, Table 1), formation of bundles of carbon nanotubes with diameters ranging from 15 to $50 \mathrm{~nm}$ and lengths of a few hundreds of nanometers can be observed, scarcely distributed on the surface (see SEM micrograph of Fig. 2B): a thinner carbon layer is deposited and $\mathrm{Ni}$ nanoparticules are identified on tips of CNTs. The associated Raman spectrum (Fig. 3) exhibits weaker and broadened D and G peaks, compared with the peaks of sample 1 . The smaller amount of carbon deposition as well as the growth of some bundles of CNTs can be correlated with the higher concentration of the activated etching species $\left(\mathrm{H}, \mathrm{NH}_{2}\right)$ generated by the presence of ammonia which is easily decomposed by the dc discharge, as discussed previously. By increasing the amount of ammonia introduced in the gas mixture (samples 3 to 5, Table 1), an increased formation of carbon nanotubes is observed: Fig. 2C shows, for the sample 5 prepared with $90 \% \mathrm{NH}_{3}$, a surface uniformly covered by aligned carbon nanotubes with diameters ranging from 15 to $100 \mathrm{~nm}$ and lengths ranging from 100 to $300 \mathrm{~nm}$. The corresponding

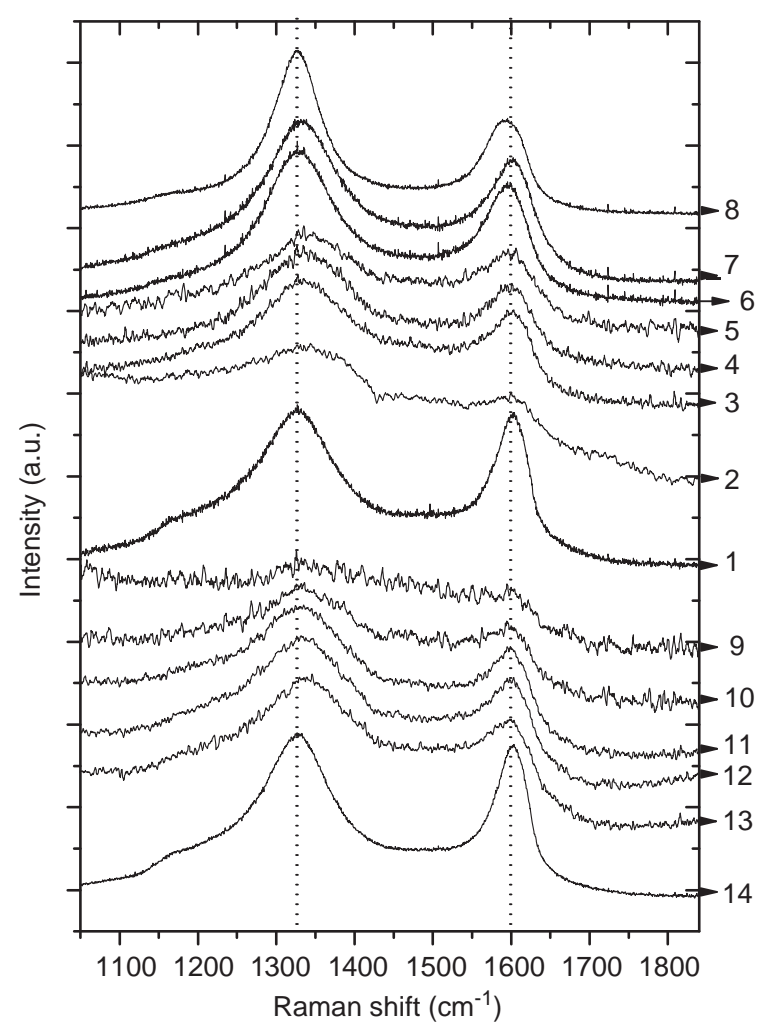

Fig. 3. Sequence of Raman spectra recorded for samples 1 to 14 (see Table 1).

Raman spectra (Fig. 3) confirm, through the decrease of the $\mathrm{I}_{\mathrm{D}} / \mathrm{I}_{\mathrm{G}}$ ratio when $\left[\mathrm{NH}_{3}\right]$ increases, the improvement of the CNT structure: both the amount of amorphous carbon and of defective structure in CNTs decrease.

The HWCVD growth mode was studied for gas mixtures containing $10 \% \mathrm{C}_{2} \mathrm{H}_{2}$ and an increasing amount of $\mathrm{NH}_{3}$ diluted in $\mathrm{H}_{2}$ (Table 1, samples 6 to 8). The HWCVD process generates atomic hydrogen and $\mathrm{C}_{n} \mathrm{H}_{n}$ radicals with $n=1,2$ [18], depending on the filament temperature $T_{f}$. When $T_{f}$ is set at $1800-\mathrm{C}$, the various gases are mostly dissociated at the contact of the tungsten wire or close to the wire. For these samples, dense tangled and curled up nanotubes are observed by SEM (Fig. 2D). The diameters of the nanotubes range from 15 to $60 \mathrm{~nm}$ and their lengths are several micrometers. The corresponding Raman spectra (Fig. 3) show, first the highly graphitic nature of the deposited samples, then the increase of the $\mathrm{I}_{\mathrm{D}} / \mathrm{I}_{\mathrm{G}}$ ratio when $\left[\mathrm{NH}_{3}\right]$ increases, which could suggest that $\mathrm{NH}_{2}$ radicals generated at high concentration deteriorate the CNT structure.

The use of both the dc plasma and the hot-wire leads to a high rate of transformation of gas molecules in the gas mixture into ions, radicals and activated molecules. So with the HW dc PECVD process, we first investigated the influence of the filament temperature (samples 9 to 11), taking as $\mathrm{C}_{2} \mathrm{H}_{2} / \mathrm{NH}_{3} / \mathrm{H}_{2}$ ratio the ratio of sample 2 (Table 1 ). Apart from the fact that sample 9 is equivalent to sample 2 because $\mathrm{NH}_{3}$ and $\mathrm{H}_{2}$ molecules are not significantly dissociated when the filament temperature $T_{f}$ is as low as 


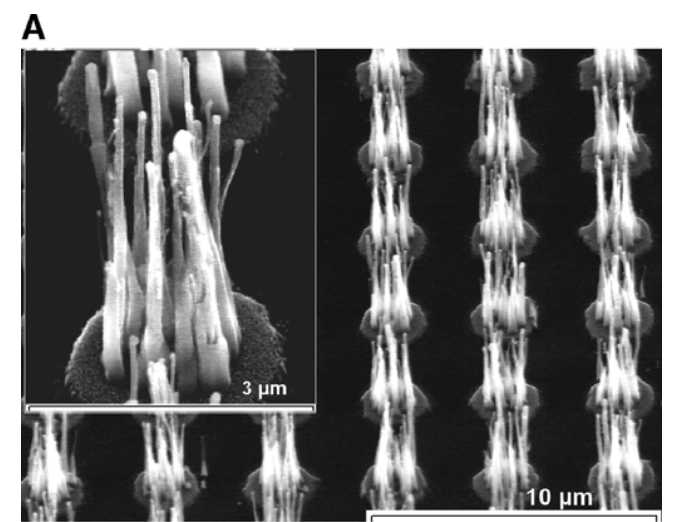

B

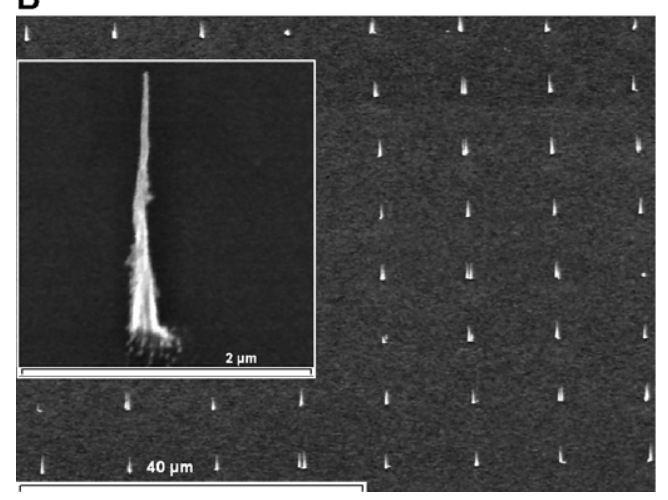

Fig. 4. Sequence of SEM images (observation angle 45-) on: (A) sample 15; (B) sample 16.

1100 -C, increase of $\mathrm{T}_{\mathrm{f}}$ results in the formation of CNTs with a small amount of amorphous carbon due to the efficient etching effect of $\mathrm{H}$ radicals, as observed in the Raman spectra (Fig. 3). Setting $\mathrm{T}_{\mathrm{f}}$ at $1800-\mathrm{C}$ and increasing the $\mathrm{H}_{2} / \mathrm{NH}_{3}$ ratio improves the CNT growth: Fig. $2 \mathrm{E}$ and $2 \mathrm{~F}$ corresponding to samples 12 and 13, respectively, show the SEM micrographs of dense aligned carbon nanotubes with lengths ranging from 500 to $700 \mathrm{~nm}$ and diameters ranging from 15 to $100 \mathrm{~nm}$. The interpretation of these HW dc PECVD results is very similar to that of the HWCVD results. The length of the nanotubes has been observed to increase rapidly when the current density impinging on the cathode (correlated with the total pressure) increases: for instance, carbon nanotubes of 5 Am length are obtained using 3 mbar pressure corresponding to a current density in the dc-discharge of 3 to $4 \mathrm{~mA} / \mathrm{cm}^{2}$.

Using HW dc PECVD process at 3 mbar pressure and $\mathrm{T}_{\mathrm{s}}=660$-C, we have performed growth of CNTs on patterned substrates with $\mathrm{Ni}$ dots of different sizes. For sample 15 (Table 1) deposited on a patterned substrate with $1 \mathrm{Am} \mathrm{Ni}$ dots realized by UV lithography, we observed several MWCNTs with diameters less than $100 \mathrm{~nm}$ growing on each dot (Fig. 4A), whereas for sample 16 deposited on a patterned substrate with $100 \mathrm{~nm} \mathrm{Ni}$ dots realized by electron-beam lithography, we observed only one MWCNT on each Ni dot (Fig. 4B). The first I-V characteristics performed on sample 16, consisting of an array of individual
MWCNTs, gave an onset electric field of $6 \mathrm{~V} / \mathrm{Am}$ and a maximum emission current density of $0.6 \mathrm{~A} / \mathrm{cm}^{2}$ for a field of $16 \mathrm{~V} / \mathrm{Am}$. Further work is necessary, taking into account the uniformity of the nanotube length, the spacing between nanotubes, etc., in order to get efficient electron emission useful for cold-cathode flat panel FEDs or vacuum microelectronic sources [2,3,19].

\section{Conclusions}

Since the first paper dealing with the preparation of CNTs by an activated CVD process [4], many workers tried to control the growth of aligned CNTs by the use of various CVD methods and to understand the mechanisms of CNT nucleation and growth.

The present study has been restricted to the use of two specific CVD methods: the hot-wire CVD and the dc plasma-enhanced CVD, working separately or in a combined action. Fixing the diffusion barrier thickness, the catalyst thickness, the substrate temperature and the pressure in the reactor, only the relative composition of the gases, the filament temperature and the potential drop between the anode and the cathode could vary in the experiments. In these conditions, we observed that using the dc PECVD process exclusively, with a potential drop of around $400 \mathrm{~V}$, for which radicals and ions impinging on the cathode were generated, growth of aligned carbon nanotubes was favored. Moreover, the CNT structure was improved when ammonia replaced molecular hydrogen as the etching gas. When the HWCVD process was used exclusively with a filament temperature of $1800-\mathrm{C}$, for which a high concentration of atomic hydrogen was generated, dense tangled and curled up localized carbon nanotubes have been grown. However, contrary to what was observed with dc PECVD, the CNT structure was deteriorated when increasing ammonia content. Thus, combining HWCVD and dc PECVD, we observed that growth of dense aligned carbon nanotubes could be obtained if ammonia content was minimized.

The last part of this work was focused on the possibility to grow aligned MWCNTs on patterned substrates, using the $\mathrm{HW}$ dc PECVD process, in order to get rid of the screening effect which is deleterious for the field emission properties. First attempts of growth have been realized on an array of $100 \mathrm{~nm} \mathrm{Ni}$ catalyst dots realized by electron beam lithography: individual MWCNTs have been grown on each dot, thus a maximum emission current density of $0.6 \mathrm{~A} / \mathrm{cm}^{2}$ has been measured for a field of $16 \mathrm{~V} / \mathrm{Am}$. Further work should be necessary for these results to be useful for electronic applications.

\section{References}

[1] S. Iijima, Nature 354 (1991) 56.

[2] W.A. de Heer, A. Châtelain, D. Ugarte, Science 270 (1995) 1179. 
[3] P.G. Collins, A. Zettl, Phys. Rev., B 55 (1997) 9391.

[4] W.Z. Li, S.S. Xie, L.X. Qian, B.H. Chang, B.S. Zou, W.Y. Zhou, R.A. Zhao, G. Wang, Science 274 (1996) 1701.

[5] M.P. Siegal, D.L. Overmyer, P.P. Provencio, Appl. Phys. Lett. 80 (2002) 2171

[6] V.I. Merkulov, D.H. Lowndes, Y.Y. Wei, G. Eres, E. Voelkl, Appl. Phys. Lett. 76 (2000) 3555.

[7] M. Chhowalla, K.B.K. Teo, C. Ducati, N.L. Rupesinghe, G.A.J. Amaratunga, A.C. Ferrari, D. Roy, J. Robertson, W.I. Milne, J. Appl. Phys. 90 (2001) 5308.

[8] O.M. Küttel, O. Groening, C. Emmenegger, L. Schlapbach, Appl. Phys. Lett. 73 (1998) 2113.

[9] C. Bower, O. Zhou, W. Zhu, D.J. Werder, S. Jin, Appl. Phys. Lett. 77 (2000) 2767.

[10] X. Wang, Z. Hu, Q. Wu, X. Chen, Y. Chen, Thin Solid Films 390 (2001) 130.
[11] Z.F. Ren, Z.P. Huang, J.W. Xu, J.H. Wang, P. Bush, M.P. Siegal, P.N. Provencio, Science 282 (1998) 1105

[12] J.H. Han, W.S. Yang, J.B. Yoo, C.Y. Park, J. Appl. Phys. 88 (2000) 7363.

[13] Y. Hayashi, T. Negishi, S. Nishino, J. Vac. Sci. Technol., A 19 (2001) 1796.

[14] T. Ono, H. Miyashita, M. Esashi, Nanotechnology 13 (2002) 62.

[15] K.H. Park, S. Choi, K.M. Lee, S. Lee, K.H. Koh, J. Vac. Sci. Technol., B 19 (2001) 958.

[16] A.C. Dillon, A.H. Mahan, J.L. Alleman, M.J. Heben, P.A. Parilla, K.M. Jones, Thin Solid Films 430 (2003) 292.

[17] D. Hash, D. Bose, T.R. Govindan, M. Meyyappan, J. Appl. Phys. 93 (2003) 6284

[18] Y.A. Mankelevich, N.V. Suetin, J.A. Smith, M.N.R. Ashfold, Diamond Relat. Mater. 11 (2002) 567.

[19] H. Schmid, H.W. Fink, Appl. Phys. Lett. 70 (1997) 2679. 